\title{
Groundnut Market Participation in the Upper West Region of Ghana
}

\author{
Benjamin Musah Abu \\ Department of Economics and Entrepreneurship Development \\ University for Development Studies, Wa, Campus \\ Email: abmusah@uds.edu.gh \\ DOI//http://dx.doi.org/10.4314/gjdsv12i1\&2.7
}

\begin{abstract}
Agricultural commercialisation is observed to be low in Ghana despite the focus of policy and efforts on increasing the rate of commercialisation. While there are significant differences of market commercialisation across regions, the Upper West Region has one of the least average marketed surplus ratio. Using a household survey data for the 2011 production season in the Upper West Region, this paper quantified the magnitude and direction of effects of factors influencing smallholder groundnut farmers' intensity of market participation using the Tobit model. The Household Commercialisation Index was first used to estimate the intensity of market participation. The results showed that about fifty-three percent of the output of groundnuts was sold in the region within the production year, which indicated a moderate commercialisation index. The results also indicated that marital status, output, mobile phone ownership, credit access, access to market information and form of sale were the most influencing variables to participation decisions. The paper concluded that groundnut was basically produced as a cash crop for the market to enhance household income. The paper recommends that the Ministry of Food and Agriculture needs to enhance groundnut productivity through access to extension services, use of improved and high yielding varieties as well as the use of good agronomic practices.
\end{abstract}

Keywords: Household Commercialisation Index, Tobit Model, Intensity of Market Participation, Smallholder Groundnut Farmers, Upper West Region

\section{INTRODUCTION}

Agricultural production on a large and commercialised scale is one of the most prioritised objectives of the development efforts in Ghana and Africa as a whole. Ghana is regarded as an agrarian economy, however, the challenge is that production is dominated by smallholder farmers who are predominantly rural dwellers. The implication this presents in efforts to develop agriculture is that policies should focus primarily on these 
smallholders. In response to this, policy documents such as Ghana Poverty Reduction Strategy (GPRS) I and II, Food and Agriculture Sector Development Policy (FASDEP) II and Comprehensive Africa Agriculture Development Programme (CAADP) and the World Bank (2007) have heightened the retooling of policies to prioritise access to markets by smallholder farmers as the growth and development pole of these farmers.

The northern half of Ghana has consistently been ranked the three most poverty-stricken regions in Ghana. The Upper West Region is seen as the poorest, having the least average annual per capita income of $\mathrm{GH} \$ 3,015.7$ as against the national average of GH\$5,346.9 (GSS, 2014). In the region, groundnut is one of the major crops grown and has high commercial value. It represented the highest cropped area of 127,490 hectares and yielded 196,676 metric tonnes after yam in 2010 in the region. This shows that groundnut production on a large scale would enhance income growth and subsequently ensure the achievement of food security.

Despite the focus of policy and efforts on increasing the rate of commercialisation, the level of agricultural commercialisation in Ghana is low at only 33\% (International Fund for Agricultural Development-International Food Policy and Research Institute (IFAD-IFPRI), 2011). This implies that on average only $33 \%$ of the level of production of each crop is sold in every production season. This problem is highlighted by the Swedish International Development Association (SIDA) (cited in Siziba, Kefasi, Diagne, Fatunbi \& Adekunlu, 2011) that only $10 \%$ of Sub-Saharan African smallholders produce enough marketable surpluses. While there are significant differences of market commercialisation across regions, the Upper West Region has one of the least average marketed surplus ratio of $18 \%$ only better than the Upper East Region, which has an estimate of 15\% (IFAD-IFPRI, 2011). The Northern Region has a marketed surplus ratio of $34 \%$, which is slightly higher than the national average. In the 2011 production season, 162,265 metric tonnes of groundnut was produced in the region. The implication of the commercialisation index is that out of this production level, 29,208 metric tonnes was marketed and further implies that groundnut, which has potential for increasing incomes is still widely produced as a staple crop (MiDA, 2010).

Premised on this, the question that comes to the fore is: Why is groundnut not making transition from staple to commercial crop in view of the potential it presents? And why is the level of commercialisation of smallholder farmers in the Upper West Region so low? Using groundnut, which is extensively cultivated in the region as a case study, the study addressed the factors affecting the low level of commercial participation by smallholder farmers. Specifically, the study provides responses to the following questions: What is the trend of production of groundnut in the region? What is the level of market participation by smallholder groundnut farmers? What factors determine the intensity of market participation by smallholder groundnut farmers?

The rest of the paper presents the conceptual framework, theoretical and methodological framework, results and discussion and conclusion. 


\section{CONCEPTUAL FRAMEWORK}

The three fundamental concepts underpinning this study are smallholder farmers, market participation and commercialisation. In the literature, farm size is the dominant way of characterising smallholder farmers. For example, Vermeulen and Cotula (2010) note that those who cultivate less than one hectare of land in areas of high population densities or cultivate ten hectares or more in semi-arid areas are smallholders. Ekboir, Boa and Dankyi (2002) indicate that a small-scale farmer in any region of Ghana has less than five hectares of land. MoFA (2011) maintains that smallholders have less than two hectares in size.

However, there are other perspectives of the definition of smallholder farmers. Chamberlin (2007) categorised the definition of the concept based on holding size, wealth, market orientation and levels of vulnerability to risk. In line with this, Dixon, Taniguchi, Wattenbach and Tanyeri-Arbur (2004) view smallholder farmers in terms of their limited resource endowments relative to other farmers in the sector. The possible reason the farm size criterion dominates is that, defining smallholders based on landholding is relatively the easiest and less controversial way of characterising them in empirical works. This study defines a smallholder farmer based on landholding. The MoFA standard of about two hectares is used to characterise a smallholder farmer in this study since MoFA is an authoritative institution in Ghana.

Market participation has two sides: households participating either as sellers or buyers (Barrett, 2008). Therefore market participation has a demand side; households participating as buyers, and a supply side; households participating as sellers. In empirical studies, the supply side of market participation is emphasised as studies tend to focus on that side of the equation. Based on the supply side, Ana, William, Masters and Shively (2008) defined market participation in terms of sales as a fraction of total output, for the sum of all agricultural crop production in the household, which includes annuals and perennials, locally-processed and industrial crops, fruits and agro-forestry. Some literature (Cazzuffi \& Mckay, 2012; Makhura, Kirsten \& Delgado, 2001) suggest that, generally market participation can be referred to as commercialisation of agriculture. That is, market participation is often used as a proxy for commercialisation or the two terms are basically used interchangeably. For example, Cazzuffi and McKay (2012) assert that commercialisation can be conceived of and measured in a number of ways and often understood in terms of market participation. The definition of market participation therefore hinges on the definition of agricultural commercialisation.

Agricultural commercialisation involves the transition from subsistence farming to increased market-oriented production (Omiti, Otieno, Nyanamba \& McCullough, 2009; Goletti, 2005; Pradhan, Dewina \& Minsten, 2010). Govereh, Jayne and Nyoro (1999) define agricultural commercialisation as the proportion of agricultural production that is marketed. They stress that commercialisation can be measured along a continuum from zero (total subsistence-oriented production) to unity ( $100 \%$ of production is sold). Pingali and Rosegrant (1995) argue that apart from marketing of agricultural outputs, it includes product choice and input use decisions based on the principles of profit maximisation. 
However, the use of market participation as a proxy for commercialisation has been observed to possess some inadequacies. According to Pingali (1997), agricultural commercialisation has more to offer than marketing agricultural outputs. The argument he poses is that agricultural commercialisation is attained when households' product choice and input use decisions are made based on the principles of profit maximisation. Moti, Gebremedhin and Hoeskstra (2009) assert that commercialisation is not merely about producing significant amount of cash commodities and supplying the surplus to the market. In support of the assertions of Pingali (1997) and Moti et al. (2009), Dawit, GabreMadhin and Dejene (2006) contend that commercialisation entails significantly three pillars: input versus output, sales versus purchases, and the type of commercial activity (cash crops versus other crops).

The implication of these arguments made by Pingali (1997), Moti et al. (2009) and Dawit et al. (2006) is that market participation cannot adequately measure commercialisation. Following from their arguments, market participation turns out to be a subset of commercialisation. Hence, in measuring market participation using commercialisation, one must clearly indicate which aspect of commercialisation is being used as a proxy for market participation. Therefore, based on the commercialisation literature, market participation in this study has to do with the pillar of commercialisation that strictly deals with increased output market orientation of households. With respect to the output market participation, this study takes a truncation of households' output market participation for sales only and excludes output market participation for purchases. Market participation in this study does not also include households engaging in the market to buy inputs. Therefore, the main indicator of this pillar of commercialisation that this study adopts is households engaging in the market to sell their produce.

\section{THEORETICAL AND METHODOLOGICAL FRAMEWORK}

This section presents the theoretical basis and empirical specification of model, estimation methods and study area and data collection.

\section{Theoretical basis and empirical specification of model}

The theoretical underpinnings of why farm households participate in agricultural markets can be found in the trade theory as postulated by Ricardo (Siziba et al., 2011). The theory postulates that farmers concentrate on the production of goods for which they have comparative advantage, and exchange for those they have no comparative advantage. However, trade theory fails to specifically identify determinants of market participation giving rise to a number of theoretical models (Barrett, 2008; Boughton, Mather, Barrett, Benfica, Abdula, Tschirley \& Cunguara, 2007). Barrett's stylised household's non-separable market participation behaviour model for example assumes that a farm household faces a decision to maximise utility either as a net buyer, net seller or autarchic represented in the reduced form as a function of the exogenous variables $(A, G, W, P, Z)$ capturing private asset stock, public asset stock, household-specific characteristics, commodity price and transaction costs respectively. 
This study focuses on the farmer's choice as to whether or not to participate in the crop market as a seller. Based on this, participating in the market as a seller can be a standalone model reflecting a fundamental relationship between market participation of households as sellers and some variables which serve as covariates specified as:

Market participation (as sellers)

$$
=f\left(\begin{array}{c}
\text { private asset stock }(A), \text { public asset stock }(G), \\
\text { household characterisitics }(W), \\
\text { commodity price }(P) \text { and transaction cost }(Z)
\end{array}\right)
$$

Following from equation 1 and other studies (Martey, Al-hassan \& Kuwornu, 2012; Siziba et al. 2011; Omiti et al., 2009; Boughton et al. 2007) the specific empirical model is specified as:

MarketParticipation

$$
\begin{aligned}
& =\alpha_{0}+\alpha_{1} A G E+\alpha_{2} G E N+\alpha_{3} \text { EDUC }+\alpha_{4} M A R S T+\alpha_{5} H H S I Z E+\alpha_{6} F E X P \\
& +\alpha_{7} \text { MFBO }+\alpha_{8} \text { FRMSIZE }+\alpha_{9} \text { HHINC }+\alpha_{10} \text { OFINC }+\alpha_{11} \text { OUTPUT } \\
& +\alpha_{12} \text { TEL }+\alpha_{13} \text { ACCRE }+\alpha_{14} \text { EXTCON }+\alpha_{15} \text { PRICE }+\alpha_{16} \text { MKTINFO } \\
& +\alpha_{17} \text { POS }+\alpha_{18} \text { FOS } \\
& +\varepsilon
\end{aligned}
$$

The description measurement and expected signs of variables are displayed in Table 1.

\section{Estimation methods}

The estimation of the market participation model represented in equation 2 can be achieved by first estimating the intensity of participation. This achieves the second objective of the study. The Household Commercialisation Index (HCI) proposed by Govereh et al. (1999) and Strasberg, Jayne, Yamano, Nyoro, Karanja and Strauss (1999) was used but modified to estimate the level of HCI for groundnut only and specified as:

$H C I_{i g}=\left[\frac{\text { Gross value of groundnut } \text { sale }_{i j}}{\text { Gross value of groundnut production }_{i j}}\right] * 100$

Where $\mathrm{HCI}_{\text {ig }}$ is the $i^{\text {th }}$ household commercialisation index for groundnut; the numerator is the total amount of groundnut sold by the $i^{\text {th }}$ household in the $j^{\text {th }}$ year $(j=2011$ farming season) and the denominator is the total value of output of groundnut by the $i^{\text {th }}$ household in the $j^{\text {th }}$ year. HCI is used as the proxy for market participation and serves as the dependent variable in equation 2 .

The Tobit model was employed to estimate the intensity of market participation model represented by equation 2. In empirical studies, econometric models applied to market 
participation in general typically adopt a two-step analytical approach to take care of the unobservable decision to participate and the observed degree or intensity of participation.

Table 1: Description, measurements and expected signs of variables in the intensity model

\begin{tabular}{|c|c|c|c|}
\hline Variable & Description & Measurement & Expected Sign \\
\hline $\mathrm{HCI}$ & Percentage of total output sold & $\begin{array}{l}\text { Household Commercialisation } \\
\text { Index }\end{array}$ & \\
\hline \multicolumn{4}{|c|}{ Farmer Characteristics } \\
\hline AGE & Age of the farmer & Number of years & $+/-$ \\
\hline GEN & Gender of the farmer & $\begin{array}{l}\text { Dummy: } 1 \text { = if male; } \mathrm{o}= \\
\text { otherwise }\end{array}$ & + \\
\hline EDUC & Education level of the farmer & Number of years of schooling & $+/-$ \\
\hline MARST & Marital status of farmer & $\begin{array}{l}\text { Dummy: } 1 \text { = if married; } 0= \\
\text { otherwise }\end{array}$ & + \\
\hline HHSIZE & Household size of farmer & $\begin{array}{l}\text { Number of people in the } \\
\text { household }\end{array}$ & $+/-$ \\
\hline FEXP & $\begin{array}{l}\text { Farmer's experience in groundnut } \\
\text { farming }\end{array}$ & Number of years in farming & + \\
\hline $\mathrm{MFBO}$ & Membership of farmer to an FBO & $\begin{array}{l}\text { Dummy: } 1=\text { if member; } \mathrm{o}= \\
\text { otherwise }\end{array}$ & + \\
\hline \multicolumn{4}{|c|}{ Private Assets Variables } \\
\hline FRMSIZE & $\begin{array}{l}\text { Total amount of land cultivated to } \\
\text { groundnut in the } 2011 \text { production } \\
\text { season }\end{array}$ & Hectares & + \\
\hline HHINC & Total annual household income & Ghana Cedi (GHథ) & + \\
\hline OFINC & $\begin{array}{l}\text { Proportion of off-farm income in total } \\
\text { annual household income }\end{array}$ & Ratio & $+/-$ \\
\hline OUTPUT & $\begin{array}{l}\text { Total output of groundnut produced } \\
\text { in the } 2011 \text { production season }\end{array}$ & Number of $50 k g$ bags & + \\
\hline TEL & Farmer's ownership of a mobile phone & $\begin{array}{l}\text { Dummy: } 1=\text { if yes; } \mathrm{o}= \\
\text { otherwise }\end{array}$ & + \\
\hline \multicolumn{4}{|c|}{ Public Assets/Social Capital Variables } \\
\hline ACCRE & Access to credit by farmer & $\begin{array}{l}\text { Dummy: } 1 \text { = if farmer applied } \\
\text { and received credit; } \mathrm{o}= \\
\text { otherwise }\end{array}$ & + \\
\hline EXTCON & $\begin{array}{l}\text { Farmer's contact with extension } \\
\text { officers }\end{array}$ & $\begin{array}{l}\text { Dummy: } 1=\text { if yes; } \mathrm{o}= \\
\text { otherwise }\end{array}$ & + \\
\hline PRICE & $\begin{array}{l}\text { Average price at which each } 50 \mathrm{~kg} \text { bag } \\
\text { of groundnut is sold }\end{array}$ & $\begin{array}{l}\text { Ghana Cedi }(\mathrm{GH} \phi) \text { per 5okg } \\
\text { bag }\end{array}$ & + \\
\hline \multicolumn{4}{|c|}{ Transaction Cost Variables } \\
\hline MKTINFO & $\begin{array}{l}\text { Farmer's access to market } \\
\text { information }\end{array}$ & $\begin{array}{l}\text { Dummy: } 1=\text { if yes; } 0= \\
\text { Otherwise }\end{array}$ & + \\
\hline POS & Point of sale of output & $\begin{array}{l}\text { Dummy: } 1 \text { = market centre; } \mathrm{o}= \\
\text { farm-gate }\end{array}$ & - \\
\hline FOS & Form of sale of groundnut & $\begin{array}{l}\text { Dummy: } 1=\text { unshelled; } \mathrm{o}= \\
\text { otherwise }\end{array}$ & $+/-$ \\
\hline
\end{tabular}


But this study purposively focused on only the second stage of the two-step approach. This implies that, the Tobit model was employed to restrictively assume that variables which determine the unobservable decision to participate also determine the observed degree or intensity of participation.

The Tobit model assumes that the observed dependent variable $Y_{j}$ for observations $j=1, \ldots$, n satisfy:

$$
Y_{j}=\max \left(Y_{j}^{*}, 0\right) \quad(4)
$$

Where $Y_{j}$ 's the are the latent variables derived from the classical linear regression model:

$$
Y_{j}^{*}=\beta^{\prime} X_{j}+U_{j}, Y_{j}=\left\{\begin{array}{c}
Y_{j}^{*} \text { if } Y_{j}^{*}>0 \\
0 \text { if } Y_{j}^{*} \leq 0
\end{array}\right.
$$

Where $X_{j}$ denotes vector of regressors in equation $2, \beta^{\prime}$ the corresponding vector of parameters shown as $\alpha_{31} \ldots \ldots, \alpha_{14}$ in equation 2 . The model errors $U_{j}$ are assumed to be independently normally distributed: $U_{j} \sim N\left(0, \sigma^{2}\right)$.

Since the Tobit model parameters do not directly correspond to changes in the dependent variable brought about by changes in independent variables, Greene (2003) specifies that the marginal effect on the intensity of market participation due to changes in the explanatory variable is given as:

$\frac{\partial E\left[\frac{Y_{j}}{X_{j}}\right\rceil}{\partial X_{i}}=\beta \oplus\left[\frac{\beta^{\prime} X_{i}}{\sigma}\right]$

\section{Study area and data collection}

Four agricultural districts were purposively selected because of their highest share in the production of groundnut in the 2011 production season. The selected districts were Jirapa-Lambussie, Nadowli, Wa West and Sissala East. Primary data was collected through a household survey in 21 enumeration areas involving 31 communities. A semi-structured questionnaire was designed to collect data on production and sale levels of groundnut, household-specific characteristics, private assets, public assets and transaction cost variables.

A three-stage clustered, purposive and random sampling approach was adopted to draw a sample size of 200 smallholder groundnut farmers. The three stages involved the selection of the four districts mentioned above, the selection of the 21 enumeration areas earmarked by MoFA and the 31 associated communities and the selection of the 200 groundnut farmers. The actual selection of respondents was made difficult as a result of the unavailability of a comprehensive list of groundnut farmers. To improvise a list, every community visited was divided into four blocks. In each block, a communal place (a place where people sit together) was identified and used as a starting point of preparing a list. 
People who sat together were asked to supply the names of groundnut farmers within that block. This method identified effectively male farmers rather than the female farmers. The names supplied were then used for the sampling. The identification of female farmers was done by finding out female farmers who were responsible for their families. Mostly, widows were identified and then contacted.

Secondary data on groundnut output, yield and cropped area from 2000 to 2011 was obtained from the regional office of MoFA. The dataset captured data from the said period only. This dataset was analysed and used to respond to objective one of the study.

\section{RESULTS AND DISCUSSION}

This section presents the socio-economic characteristics of farmers, trend in groundnut production, intensity of market participation and determinants of intensity of market participation.

\section{Socio-economic characteristics of surveyed households}

The mean age of household heads was 42 and ranged from 19 to 90 years. Farm households in the region can be described as relatively young and within the economically active population. About $71 \%$ of household heads was male while about $29 \%$ was female. About $80 \%$ of household heads were married. Mean household size in the region was about 10 people and ranged from 2 to 32. The majority of households (69.5\%) had no formal education. This was followed by heads with primary level of education (12.5\%). The least were heads with technical/vocational education (0.5\%). The mean years of education showed that on average the highest level of education attained by a household head was primary education (approximately primary 2). Households had on the average 15 years of farming experience in groundnut farming. The minimum and maximum farming experience were 1 and 75 years respectively. The average annual household income was $\mathrm{GH} \$ 1,135.59$ and ranged between $\mathrm{GH} \$ 35$ and $\mathrm{GH} \$ 9,100$. Household income constituted sales of groundnut output, other on-farm activities, and non-farm activities. About $44 \%$ of household heads engaged in non-farm income activities. Mean annual non-farm income was GH\$200.87.

The mean farm size cultivated was 1.22 ha with a minimum of 0.40 and maximum of 2 ha. The mean output of groundnut was 10.41 bags with a minimum of 0.15 bags and a maximum of 80 bags. Households with access to credit represented only $17 \%$ of the sample. This confirms the observation by Martey et al. (2012) that access to credit is one of the major constraints faced by households. The majority (87\%) of households were not members of any farmer organisation. Farmers who had access to market information represented the majority (91.5\%). Market information sought by farmers basically constituted groundnut prices and where sharp market for groundnut was found. Access to information was from friends/relatives (9\%), market women (20\%) and radio (25\%). Combined sources of market information from these three sources represented $46 \%$. 
Households receiving agriculture extension services constituted $19.5 \%$ of surveyed households while those without contact constituted $80.5 \%$.

About $83.5 \%$ of households sold groundnut in the 2011 farming season while about $16.5 \%$ did not sell. About $40.7 \%, 56.3 \%$ and $3 \%$ of groundnut sales were done at farm-gate, market centre and both farm-gate and market centre respectively. About $74 \%$ of groundnut was sold in the unshelled form while about $23 \%$ was shelled before selling. Quantity sold in both shelled and unshelled form represented about 3\%. The average price received by groundnut farmers was $\mathrm{GH} \$ 72.29$ per $50 \mathrm{~kg}$ bag distributing into $\mathrm{GH} \$ 79.51$ per $50 \mathrm{~kg}$ bag at farm-gate and GH\$117.93 per 5okg bag at the market centre.

\section{Trend in groundnut production}

The analysis of production data shows that groundnut production generally increased steadily over the period of 2000 to 2011 with a statistically significant annual average growth rate of $8 \%$. Production peaked markedly between 2005 and 2006 and between 2009 and 2010. Sharp declines in production were recorded in 2007 and 2011. The average yield over the same period reflects a fluctuating trend. Figure 1 shows the trend of production and cropped area and figure 2 shows the yield of groundnut.

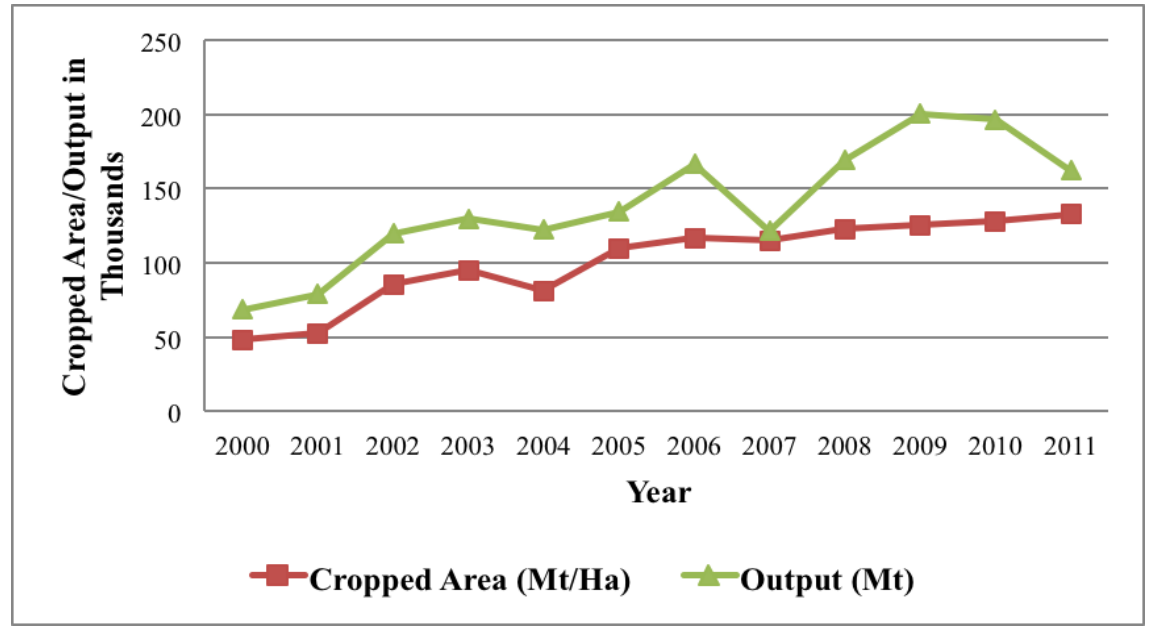

Fig 1: Trend in groundnut production and cropped area in the Upper West Region (2000 - 2011) Source: Regional office of MoFA (Wa), 2012 


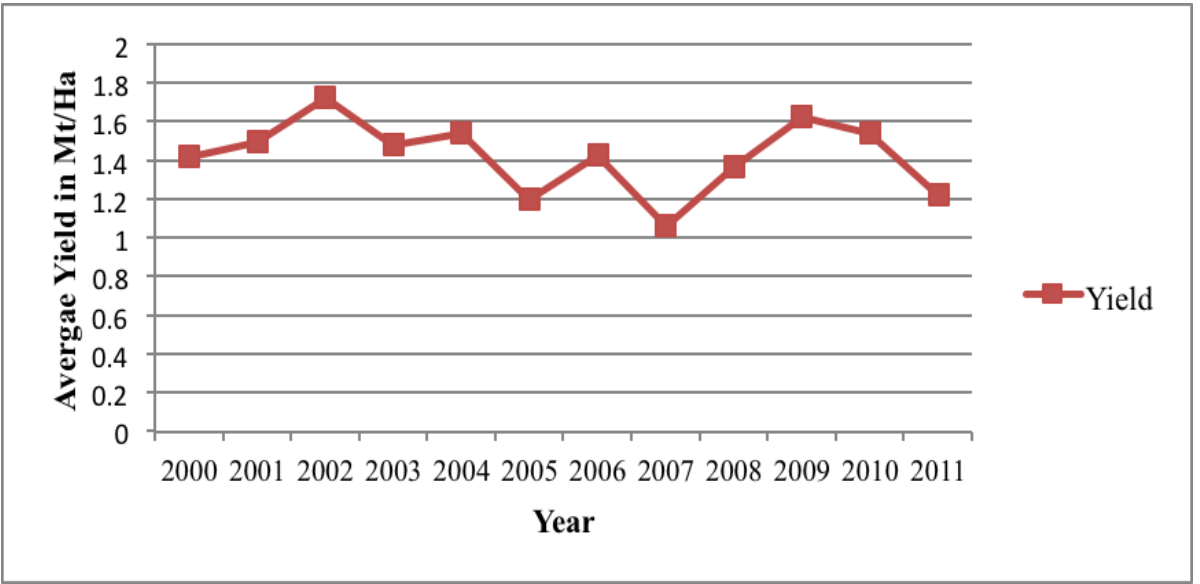

Fig 2: Trend in yield of groundnut in the Upper West Region (2000-2011)

Source: Regional office of MoFA (Wa), 2012

The trend shows that sharp declines in production especially in 2007 and 2011 are explained by poor yield. Output growth is thus explained primarily by increases in cropped area and good yield. A simple double logged regression (Table 2) shows that expansion in cropped area with a statistically significant annual average growth rate of 8.5\% explains output growth than growth in annual average yield of groundnut.

Table 2: Regression estimate

\begin{tabular}{|l|l|l|l|l|}
\hline Variable & Coefficient & Standard Error & $\mathbf{t}$ & Sig. \\
\hline Constant & 0.147 & 0.611 & 0.24 & 0.816 \\
\hline Log of cropped area & 0.993 & 0.052 & 19.067 & 0.000 \\
\hline Log of yield & 0.751 & 0.128 & 5.88 & 0.000 \\
\hline $\begin{array}{l}\text { Dependent variable: Log of output } \\
\text { F 189.02 } \\
\text { R }^{2} 0.976\end{array}$ & & & & \\
\hline
\end{tabular}

Source: Regression estimates of data from regional office of MoFA (Wa), 2012

\section{Intensity of market participation}

The analysis of the household data showed that the intensity of groundnut market participation was $52.56 \%$. This estimate indicates that the average output of groundnut sold within the 2011 production season was about $53 \%$. This indicates a moderate commercialisation index and implies that groundnut can be described as a cash crop 
produced for the market to enhance household income. For only groundnut market participants ( 167 households out of the 200 households), the level of commercialisation was about $63 \%$ and ranged from $13.33 \%$ to $100 \%$.

The individual household commercialisation indices were used to characterise farmers according to low, medium and high commercial farmers. According to Abera (2009), households who sell at most $25 \%$ and below their output are low commercial farmers, those who sell between 26 and 50\% are medium commercial farmers and above 50\% are high commercial farmers. Following this categorisation, $23 \%$ were low commercial farmers, $23 \%$ were medium commercial farmers and $54 \%$ were high commercial farmers. For only those who sold groundnut, $7.8 \%$ were low commercial farmers, $27.5 \%$ were medium commercial farmers and $64.7 \%$ were high commercial farmers. Figure 3 displays the categorisation of households.

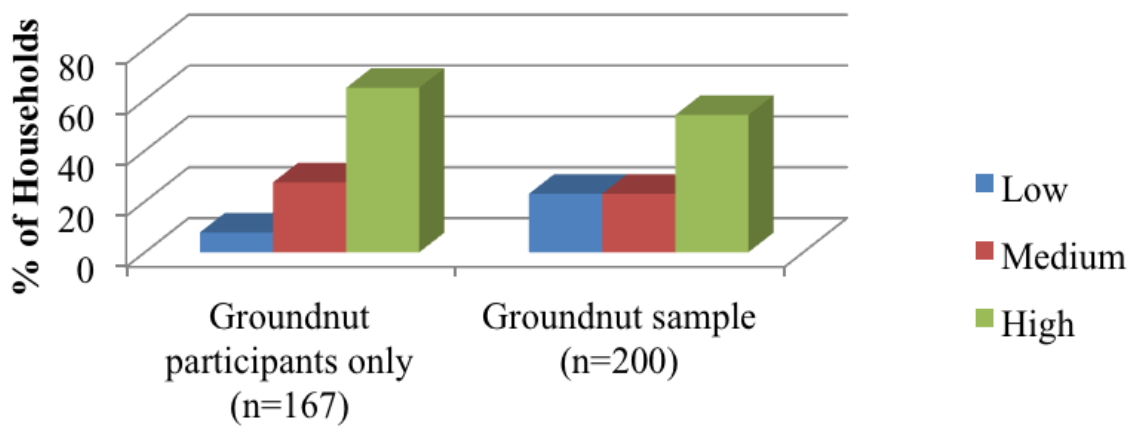

Participants and Non-particpants

Fig 3: Characterisation of intensity of participation by households

Source: Drawn from household survey data, 2012

The observation shows that for market participants only and for the whole sample, more households were high commercial farmers than medium farmers and more medium commercial farmers than low commercial farmers except for the latter where the whole sample has the same percentage of medium and low commercial farmers. This near consistency further reinforces the argument that groundnut is basically a cash crop in the region. 


\section{Determinants of the intensity of market participation}

Stata was used for the estimation of the Tobit model. Diagnostic test for multicollinearity was conducted based on variance inflation factor (VIF) to identify any potential misspecification problems that may exist in the estimated model. The presence of such a problem leads to estimates that are unstable and have high standard errors resulting in the insignificance of most or all the explanatory variables. The test indicated that the largest VIF in the model was 3.47, which is below the maximum value of 10 that is used as a rule of thumb to indicate the presence of multicollinearity. This implies that multicollinearity is not a problem in the estimated model. Heteroscedasticity is identified as a common problem with typical cross-section data. The established procedure for the correction of heteroscedasticity is to estimate the models using robust standard errors. The model is estimated using robust standard errors to correct for heteroscedasticity. The results are displayed in Table 3.

The $F$ statistic value of 21.29 is statistically significant at $1 \%$ indicating that the explanatory variables jointly explain the intensity of participating in the market. The significant determinants of the intensity of participating in the groundnut market are age of the household head, gender of household head, marital status of the household head, experience in groundnut farming, annual household income, output of groundnut, ownership of mobile phone, access to credit, access to market information, point of sale of groundnut output and form of sale of groundnut. 
Table 3: Tobit estimates of determinants of the intensity of market participation

\begin{tabular}{|c|c|c|c|}
\hline Variable & Coefficient & $\begin{array}{l}\text { Robust Standard } \\
\text { Error }\end{array}$ & Marginal Effect \\
\hline CONSTANT & $35 \cdot 7121^{* * *}$ & 9.0199 & \\
\hline AGE & $-0.2102^{*}$ & 0.1076 & -0.0024 \\
\hline GEN & $-6.3040^{*}$ & 3.6114 & -0.0111 \\
\hline EDUC & 0.3166 & 0.3090 & 0.0004 \\
\hline MARST & $6.3588^{* *}$ & 3.1542 & 0.0051 \\
\hline HHSIZE & 0.0979 & 0.2461 & 0.0001 \\
\hline FEXP & $0.2165^{*}$ & 0.1174 & 0.0025 \\
\hline MFBO & 0.4083 & $3 \cdot 5128$ & 0.0005 \\
\hline FRMSIZE & -1.7769 & 4.1595 & -0.0020 \\
\hline HHINC & $0.0013^{*}$ & 0.0008 & $1.50 e-06$ \\
\hline OFINC & -0.4401 & $5 \cdot 3038$ & -0.0005 \\
\hline OUTPUT & $0.8964^{* * *}$ & 0.3411 & 0.0102 \\
\hline TEL & $9.0427^{* * * *}$ & 3.2043 & 0.0077 \\
\hline ACCRE & $7 \cdot 3766^{* *}$ & 3.5982 & 0.0132 \\
\hline EXTCON & 0.9721 & 3.0683 & 0.0012 \\
\hline PRICE & -0.0287 & 0.0768 & -0.0003 \\
\hline MKTINFO & $12.6113^{* * *}$ & $3 \cdot 3731$ & 0.0057 \\
\hline POS & $-4.8528^{*}$ & 2.4909 & -0.0654 \\
\hline FOS & $7.5118^{* *}$ & 3.4447 & 0.0065 \\
\hline $\begin{array}{lc}\text { No. of observations } & 167 \\
\text { F }(18,149) & 21.29^{* * *} \\
\text { Pseudo R } & 20.0984 \\
\text { Log pseudo likelihood } & -660.2632 \\
{ }^{* * *} \text { p }<0.01,{ }^{* *} \text { p }<0.05 \text { and }{ }^{*} \text { p }<0.10\end{array}$ & & & \\
\hline
\end{tabular}

Source: Regression estimates from household survey data, 2012

Age is negatively correlated with the quantity of groundnut sales. This implies that older farmers sell less groundnuts as compared to younger farmers. An increase in the age of a farmer by one year reduces the intensity of participation by $0.2 \%$. It is observed that 
older farmers prioritise the enhancement of food security as against draining their reserves to participate in the market. Younger farmers on the other hand prioritise the enhancement of their quality of life and would drain their reserves to engage in the market. The gender variable indicates that males sell less groundnuts as compared to their female counterparts. For a male headed household, the intensity of participation would have increased by $1 \%$ if the head was a female. This finding contradicts the observation of Cunningham, Brown, Anderson and Tostao (2008) that men are likely to sell more grain early in the season when prices are still high, while women prefer to store more output for household self-sufficiency. A possibility for this rather unexpected finding is informed by the observation that female household heads were either widows or had their husbands incapacitated to act as heads. The implication emanating from this observation is that female headed households would have to sell more groundnuts in order to shoulder social and economic responsibilities as heads.

Marital status is positively correlated with the quantity of groundnut sold. This means that married household heads sell more quantity of groundnut than unmarried heads. The quantity offered for sale increases by $0.5 \%$ for married households. Married farmers have more economic and social responsibilities to meet and hence have to sell more groundnuts to cater for such needs. This finding is supported by the observation in the region that married heads collectively engage in farming activities and receive the full support of their spouses as though they are operating a partnership kind of venture. This influences large production. Farming experience is positively correlated with the amount of groundnut sold. The intensity of participation increases by about $0.3 \%$ for an additional year of experience. This is consistent with the finding of Martey et al. (2012) that experienced household heads are able to take better production decisions and have greater contacts, which allow trading opportunities to be discovered at lower cost. Also, more experienced farmers over time have acquired some understanding of market dynamics and therefore improve decisions about the amount of output sold (Makhura et al., 2001). This positive correlation contradicts the negative correlation of age since it is expected that older people would have acquired greater experience in farming than younger people. However, the difference in the measurement of these two variables accounts for the differing results. While age was measured with absolute years lived, experience was measured by the specific years a farmers cultivated groundnut. With this, the interplay of some older farmers having cultivated groundnut for less years and young farmers having cultivated groundnut for longer years is responsible for the results.

Household income positively influences the quantity of groundnut sold. For a GH\$1 increase in annual household income, quantity increases by $0.000002 \%$. Higher household income presents the opportunity for cultivating large farm sizes and purchasing productivity enhancing inputs leading to high output and then large marketable surpluses. The quantity of groundnut produced is associated with a higher level of groundnut sales. For every extra $50 \mathrm{~kg}$ bag of production, the intensity of participation increases by 1\%. This confirms the findings of Omiti et al. (2009) and Barrett (2008) that surplus production serves as incentive for a household to participate in 
market. Ownership of telephone is positively associated with the quantity of groundnut sales. The extent of sale increases by $0.7 \%$ if a household head owns a mobile phone. This is consistent with Olwande and Mathenge (2012) who found that the ownership of communication equipment such as radio, television and/or phone has positive and significant influence on the amount sold. The possible reason for this finding is that ownership of a mobile phone by a farmer provides the potential of sourcing market information from diverse sources which boosts the quantity sold. This finding buttresses the importance of market information in the marketing behaviour of households. Access to credit increases the quantity of groundnut sold. Households who have access to credit have their extent of participation increasing by about $1 \%$. One plausible reason could be that, households with access to credit need to raise enough funds to pay back their debts/ loans. Also, it is possible that lenders might be interested in lending to farmers who are market-oriented consistently in order to redeem their funds, hence those who had access to credit are noted for their high degree of sales.

Access to market information has a positive association with the quantity of groundnut sold. The quantity sold increases by $0.5 \%$ for households with market information. According to Martey et al. (2012), market information guarantees producers flow of insights on market requirements and opportunity sets that enable farmers to plan effectively. The effect of transaction cost captured by the point of sale of output negatively influences the quantity of groundnut sold. This implies that farm-gate sellers sell more groundnut than market centre sellers. The extent of groundnut sales decreases by about $7 \%$ for market centre sellers. The average price of farm-gate sale of groundnut was GH $\$ 71.40$ per $50 \mathrm{~kg}$ bag while the market centre average was GH $\$ 115.40$ per 5okg bag. Given that higher prices prevail in market centres and yet more output is sold at the farm-gate, it can be deduced that transaction cost has a role to play in explaining why more output of groundnut is sold at the farm-gate. About sixty-four percent of groundnut households indicated that they sold at the farm-gate to avoid paying transportation fare or incurring other costs to get to market centres that offer higher prices.

The form groundnut was sold has a positive effect on the quantity of groundnut sold. This means that, the intensity of participation increases by about $0.7 \%$ for households who sold groundnut in the unshelled form. A reason supporting this finding is that, shelling of groundnut is a labour intensive, time consuming and tedious activity. Therefore, households turn to sell without shelling so that they could have the time to engage in other activities. Another reason could be that, most smallholders sell their output immediately after harvest and are unable to store their output for later processing (shelling).

\section{CONCLUSION}

Groundnut production over the years has been increasing steadily with an annual average growth rate of $8 \%$. Output expansion is primarily accounted for by expansion in area 
under cultivation and yield increases. However, expansion in cropped area explains output expansion more than yield increases. This calls for policy makers and other stakeholders such as the Crop Research Institute (CRI) of the Council for Scientific and Industrial Research (CSIR) and Alliance for Green Revolution in Africa (AGRA) to step up efforts to ensure that groundnut output growth is driven by yield and productivity surge instead of cropped area expansion.

The index of commercialisation showed that about $53 \%$ of groundnut was sold by all the sampled farmers while about 63\% was sold by only market participants in the 2011 production season, an indication that groundnut is produced as a cash crop to enhance household income. With respect to the characterisation of farmers, $23 \%$ of groundnut farm households are characterised as low commercial farmers, $23 \%$ as medium commercial farmers and $54 \%$ as high commercial farmers respectively.

Most significant determinants of the intensity of participation in the groundnut market in terms of both the levels of significance and magnitude of effect are output of groundnut, ownership of a mobile phone, access to credit, access to market information and the form groundnut is sold. Most significant determinants in terms of only the magnitude of effect are gender and point of sale. These variables have proven to be decision or policy variables.

The study recommends that productivity enhancing mechanisms are needed to be put in place by MoFA. This strengthens the position of public agricultural research into improvements in yields and developments of groundnut enhancing agroinputs. This should be coupled with the delivery of effective extension service with effective monitoring and supervision. The Village Infrastructure Project (VIP) should consider public investments in the development of modern market centres at vantage communities. The department of feeder roads and the Ghana Highways Authority should target the upgrading of rural roads as this would reduce transportation cost and hence stimulate the desire of farm households to participate in these marketing centres. MoFA and other stakeholders should establish rural agricultural finance scheme aimed at addressing the credit needs of smallholder farmers.

The Statistics, Research and Information Directorate (SRID) of MoFA should be more professional and well-resourced to enable it collaborate with other stakeholders such as radio stations to get relevant information to farmers on time. Farmers are encouraged to invest in the acquisition of market information through the purchase of mobile phones and radio sets and establish effective linkage with marketing centres and to participate in extension programmes and take advantage of the services rendered by extension agents on production and productivity enhancing measures. This would improve their production levels for greater market engagements.

This paper is limited in its inability to consider the probability of participating in the groundnut market as well as not considering the three categories of net buyer (households whose net sales are negative), autarchic (households whose net sales are 
equal to zero), and net seller (households whose net sales are positive) as indicated by Bellemare and Barrett (2006), and Barrett (2008). This limitation is technical but does not pose analytical consequences since they showed that each of the divisions of market participation can be made to stand alone.

\section{ACKNOWLEDGEMENT}

The author is grateful to the International Food Policy Research Institute (IFPRI), Ghana for providing funds for data collection and allowing the use of the data.

\section{References}

Abera, G. (2009). Commercialisation of smallholder farming: determinants and welfare outcomes. A Cross-sectional study in Enderta District, Tigrai, Ethiopia. Master Thesis submitted to the University of Agder, Kristiansand, Norway, pp. 54-55.

Ana, R., William, R., Masters, A. and Shively, G.E. (2008). Linkages between market participation and productivity: results from a multi-country farm household sample. A paper prepared for presentation at the American Agricultural Economics Association Annual Meeting. Orlando, FL, July 27-29, 2008.

Barrett, C.B. (2008). Smallholder market participation: Concepts and Evidence from Eastern and Southern Africa. Food Policy, 33(2008), pp. 299-317.

Boughton, D., Mather, D., Barrett, C.B., Benfica, R., Abdula, D., Tschirley, D. and Cunguara, B. (2007). Market participation by rural households in a low-income country: An asset-based approach applied to Mozambique. Faith and Economics, 5o(Fall 2007), pp. 64-101.

Cazzuffi, C. and McKay, A. (2012). Rice market participation and channels of sale in rural Vietnam. In selected paper prepared for presentation at the International Association of Agricultural Economists (IAAE) Triennial Conference. Brasil (18-24 August).

Chamberlin, J. (2007). Defining smallholder agriculture in Ghana: Who are smallholders, what do they do and how are they linked with markets? Ghana Strategy Support Program. Background Paper No.GSSP ooo6.

Cunningham, L.T., Brown, B.W., Anderson, K.B. and Tostao, E. (2008). Gender differences in marketing styles. Agricultural Economics, 38(1), pp. 1-7.

Dawit, A., Gabre-Madhin, E. and Dejene, S. (2006). From farmer to market and market to farmer: characterising smallholder commercialisation in Ethiopia. In Paper submitted for ESSP policy conference on bridging, balancing, and scaling up: advancing the rural growth Agenda in Ethiopia. Addis Ababa, Ethiopia. 
Dixon, J., Taniguchi, K., Wattenbach, W. and Tanyeri-Arbur, A. (2004). Smallholders, globalisation and policy analysis. Rome, FAO. AGSF Occasional Paper 5.

Ekboir, J., Boa, K. and Dankyi, A.A. (2002). Impacts of no-till technologies in Ghana. Mexico D.F.:CIMMYT.

Ghana Statistical Service (2014). Ghana living standards survey report of the fifth round. Accra, Ghana.

Goletti, F. (2005). Agricultural commercialisation, value chains and poverty reduction. Making Markets Work Better for the poor, ADB/DFID. Agrifood Consulting International.

Govereh, J., Jayne, T.S. and Nyoro, J. (1999). Smallholder commercialisation, interlinked markets and food crop productivity: Cross-country evidence in Eastern and Southern Africa. The Department of Agricultural Economics and The Department of Economics, Michigan State University (MSU).

Greene, W.H. (2003). Econometric analysis. (5th ed.). Upper Saddle River, New Jersey: Prentice Hall.

International Fund for Agricultural Development-International Food Policy Research Institute (2011). Agricultural commercialisation in northern Ghana. Innovative Policies on Increasing Access to markets for High-Value Commodities and Climate Chane Mitigation. Accra, Ghana: IFAD-IFPRI Partnership Newsletter.

Makhura, M.-N., Kirsten, J. and Delgado, C. (2001). Transaction costs and smallholder participation in the maize market in the Northern Province of South Africa. In Seventh Eastern and Southern Africa Regional Maize Conference. Pretoria, South Africa. (11-15 February), pp. 463-467.

Martey, E., Al-hassan, R.M. and Kuwornu, J.K.M. (2012). Commercialisation of smallholder agriculture in Ghana: A Tobit regression analysis. African Journal of Agricultural Research, 7(14), pp. 2131-2141.

Millennium Development Authority (2010). Investment opportunity in Ghana: Maize, soya and rice production and processing. Accra, Ghana.

Ministry of Food and Agriculture (2007). Food and agriculture sector development policy II (FASDEP II). Accra, Ghana.

Moti, J., Gebremedhin, B. and Hoeskstra, D. (2009). Smallholder commercialisation: Processes, determinants and impact. Discussion Paper No. 18. Improving productivity and market success (IPMS) of Ethiopian Farmers Project. International Livestock Research Institute (ILRI). Nairobi, Kenya. 
Olwande, J. and Mathenge, M. (2012). Market participation among poor rural households in Kenya. proceedings of the Triennial Conference of the International Association of Agricultural Economists, (18-24 August), Brasil.

Omiti, J.M., Otieno, D.J., Nyanamba, T.O. and McCullough, E. (2009). Factors influencing the intensity of market participation by smallholder farmers: A case study of rural and peri-urban areas of Kenya. African Journal of Agricultural and Resource Economics, 3(1), pp. 57-82.

Pingali, P.L. (1997). From subsistence to commercial production system: The transformation of Asian agriculture. American Journal of Agricultural Economics, 79(2), pp. 628-634.

Pingali, P.L. and Rosegrant, M.W. (1995). Agricultural commercialisation and diversification: Process and polices. Food Policy, 20(3), pp. 171-185.

Pradhan, K., Dewina, R. and Minsten, B. (2010). Agricultural commercialisation and diversification in Bhutan. International Food Policy Research Institute (IFPRI). Washington, DC, USA.

Siziba, S., Kefasi, N., Diagne, A., Fatunbi, A.0. and Adekunle, A.A. (2011). Determinants of cereal market participation by sub-Saharan Africa smallholder farmer. Learning Publics Journal of Agriculture and Environmental studies, 2(1), pp. 180-193.

Strasberg, P.J., Jayne, T.S., Yamano, T., Nyoro, J., Karanja, D. and Strauss, J. (1999). Effects of agricultural commercialisation on food crop input use and productivity in Kenya. Michigan State University International Development Working Papers No. 71. Michigan, USA.

Vermeulen, S. and Cotula, L. (2010). Making the most of agricultural investment: A survey of business models that provide opportunities for smallholders. IIED/FAO/IFAD/SDC, London/Rome/Bern.

World Bank (2007). World Development Indicators. Washington, DC: Green Press Initiative. 